\title{
retten!
}

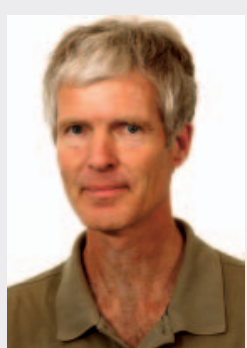

Dr. Sönke Müller

\section{Unfälle mit Tieren}

Hätten Sie es gewusst?

„Im Normalfall werden Raubtiere erst versuchen zu flüchten. Der Angriff erfolgt dann, wenn sie sich selbst bedrängt fühlen."

Also keinerlei Grund zur Sorge, wenn Sie wieder einmal im Zoo oder im Zirkus (die haben aber bald ja keine Tiere mehr) die gebissenen (oder gerissenen) Menschen retten müssen?

Nein, ganz so einfach ist es nicht, denn nicht alles, was sich an giftigen oder gefährlichen Tieren in unserem Lande aufhält - natürlicherweise oder aber als exotische Import-Haustiere -, flieht spontan vor den Trägern von Rettungsdienstjacken.

Was also tun, wenn man es mit einer banalen heimischen Kuh zu tun bekommt, die den Melker getreten hat? Was tun mit Herrchens treuem Hund, der nicht einsieht, dass der Rettungsdienst nun an den leblosen Menschen heran muss? Wie gehe ich taktisch vor (s. GAMS-Regel im Beitrag!), wie versuche ich herauszubekommen, um welche exotische Giftnatter es sich in der Privatwohnung handeln könnte? Das alles und noch viel mehr wird Ihnen der Artikel von Dr. Tiesmeier und Kollegen zum Thema „Notfälle mit Tieren im Rettungsdienst - Einsatztaktik und Erstversorgung“ nahebringen.

Eine zahlenmäßig im Rettungsdienst sicherlich erheblich größere Relevanz kommt einer Sportart zu, bei der sich in Deutschland ca. 1,25 Millionen Menschen ständig freiwillig einer Tierart - nämlich dem Pferd - nähern, dem Reitsport!

Der Klassiker „Sturz vom Pferd, V.a. SHT, V.a. Wirbelsäulentrauma“ zählt zu den Einsatzkategorien, die bei allen Beteiligten stets höchste Anspannung verursachen.

Was wird uns erwarten? Wird das Gelände überhaupt zugänglich sein? Wird der Betroffene nur eine Bagatellverletzung oder ein Polytrauma haben? Droht hier einem meist jungen, meist weiblichen Patienten ein SHT oder eine Querschnittlähmung? Dieser Fragen haben sich die Autoren Goltz/Drechsler in dem Beitrag über Reitunfälle angenommen.

Und zum Schluss wiederum ein Tipp der Autoren des Beitrags „Notfälle mit Tieren im Rettungsdienst - Einsatztaktik und Erstversorgung“, der aber ggf. auch auf Menschen angewandt werden und somit das Problem mit den Schaulustigen lösen könnte:

„Wenn ein Hund Arbeiten am Patienten behindert, lässt er sich manchmal durch die Gabe von Futter [...] fortlocken und im Nebenraum einsperren.“

Ihr

Dr. Sönke Müller 